\title{
Condicionalidades de saúde do Programa Bolsa Família: reflexões a partir de um centro médico municipal no Rio de Janeiro ${ }^{1 .}$
}

\section{Bolsa Família Program health conditionalities: reflections from a local health center in Rio de Janeiro.}

\section{Condicionalidades de salud del Programa Bolsa Familia: reflexiones a partir de un centro de salud local en Río de Janeiro.}

Maria Raquel Passos LIMA ${ }^{2}$ Liliane dos Anjos PONTES ${ }^{3}$ Denise Oliveira e SILVA ${ }^{4}$

RESUMO: Este artigo descreve e analisa a experiência de acompanhamento de mulheres beneficiárias do Programa Bolsa Família em um centro de saúde municipal na zona oeste do Rio de Janeiro. Através de pesquisa empírica, busca-se contribuir com dados qualitativos para a compreensão do universo que envolve o cumprimento das condicionalidades exigidas por essa política social. A metodologia utilizada é a observação participante empreendida nos atendimentos semanais oferecidos às participantes do Programa. As condições materiais e as atividades práticas que envolviam a realização das consultas nutricionais são apresentadas, assim como a relação destas com a gestão da estrutura burocrática que rege o funcionamento da instituição. Na conclusão, são discutidos os fatores que se tornam limitantes dentro desta estrutura e, sua relação com as beneficiárias, assim como as estratégias desenvolvidas pelos gestores e profissionais de saúde para contorná-los. A análise demonstra a complexidade de fatores que incidem sobre o cumprimento das condicionalidades do PBF nas unidades de saúde, problematizando perspectivas que tendem 1 Esta pesquisa faz parte do projeto Núcleo de Segurança Alimentar e Nutricional do Centro Oeste (NUSAN-CO) financiado pela FINEP através do convênio No 04.10 .0517 .00 com a Diretoria Regional de Brasília da Fundação Oswaldo Cruz como ação do Projeto Cidade Saudável do Programa DF Sem Miséria TC FUNASA/FIOCRUZ- Direb Desenvolvimento Institucional.

2 Doutora em Ciências Humanas (Antropologia Cultural) e Mestre em Sociologia (com ênfase em Antropologia) pela UFRJ. Antropóloga. Programa de Pós-Graduação em Sociologia e Antropologia da UFRJ.Endereço: R. General Polidoro, 20/603. Botafogo. Rio de Janeiro. CEP 22280-005. RJ - Brasil.

E-mail: mariarpl@yahoo.com.br

3 Especialista em Saúde Pública com aperfeiçoamento em Alimentação e Cultura pela ENSP/Fundação Oswaldo Cruz. Nutricionista - Tutora em ensino a distância ENSP/FIOCRUZ. Endereço: R. Elmo Correa, 347. Bangu. Rio de Janeiro. CEP 21850-010. RJ - Brasil. E-mail: dosanjos.liliane@gmail.com

4 Pós-Doutora em Antropologia da alimentação pela EHESS/Paris e Doutora em Ciências da Saúde pela UNB. Nutricionista -Pesquisadora DE da Fundação Oswaldo Cruz e coordenadora do Programa de Alimentação, Nutrição e Cultura (PALIN/FIOCRUZ-Brasília).Endereço: MLN, MI 12, Rua 03 Lote b 05 Casa 02, Cond. Porto Seguro, Lago Norte. Brasília. Cep 71540-120. DF - Brasil.

E-mail: deniluz@fiocruz.br 
a responsabilizar moralmente as mães, apontando a sua conduta como fator exclusivo do qual depende a realização das contrapartidas exigidas.

Palavras-chave: Condicionalidades de saúde; Programa Bolsa Família; Atenção Básica à Saúde.

\begin{abstract}
This article describes and analyzes the experience of the BolsaFamilia Program (PBF) beneficiaries in a municipal health centre in the West zone of Rio de Janeiro. Through empirical research, we seek to contribute with qualitative data for understanding the universe which involves fulfill theconditionalities required by this social policy. The methodology used is the participant observation, carried out through weekly medical consultations offered to program participants. The material conditions and the practical activities involving the nutritional consultations are presented, as well as their relationship with the management of the bureaucratic structure that governs the functioning of the institution. In conclusion, the factors which become limitations within this structure are discussedin relation with the beneficiaries experiences, as well as the strategies developed by managers and health professionals to bypass them. The analysis demonstratesthe complexity of factors that affect the possibility of fulfilling PBF conditionalities in the health units, questioning perspectives that tend to morally responsible mothers, pointing his conduct as the sole factor which depends on the implementation of counterparts measures required.
\end{abstract}

Keywords: Health Conditionalities; BolsaFamíliaProgram; Primary Health Care

RESUMEN: En este artículo se describe y analiza la experiencia de las mujeres beneficiarias de seguimiento del Programa Bolsa Familia en un centro de salud municipal en el oeste de Río de Janeiro. A través de la investigación empírica, buscamos aportar datos cualitativos para comprender el universo que implica el cumplimiento de las condiciones exigidas por esta política social. La metodología utilizada es la observación participante realizada en visitas semanales que se ofrecen a los participantes en el Programa. Se presentan las condiciones materiales y las actividades prácticas que implican la realización de consultas nutricionales, así como su relación con la gestión de la estructura burocrática que rige el funcionamiento de la institución. En conclusión, los factores se discuten que se convierten en la limitación dentro de esta estructura y su relación con el beneficiario, así como las estrategias desarrolladas por los directivos y profesionales de la salud para eludir ellos. El análisis muestra la complejidad de los factores que influyen en el cumplimiento de las condicionalidades de GMP en los establecimientos de salud, cuestionando perspectivas que tienden a madres moralmente responsables, señalando su conducta como el único factor que depende de la consecución de las contrapartes necesarias.

Palabras llave: condicionalidades de salud; Programa Bolsa Familia; Atención Primaria de Salud.

\title{
INTRODUÇÃO
}

O Programa Bolsa Família é uma política de transferência condicionada de renda que constitui uma das principais estratégias do Plano Brasil Sem Miséria(PBSM). O PBSM se apresenta como 
uma etapa de consolidação das políticas sociais brasileiras por meio de programas de governo com vistas à realização da seguridade social no país, prevista pela Constituição Federal do Brasil de 1988. Este programa completou 10 anos em 2013 como resultado da trajetória do Programa Fome Zero (PFZ), criado em 2003, que identificou a fome como resultado da extrema pobreza e da exclusão social e econômica e, conjugou a partir de uma abordagem interdisciplinar e de uma estratégia multisetorial, um conjunto de políticas específicas para o combate à fome e à miséria, das quais o Programa Bolsa Família é o de maior expressão (Menezes e Santarelli, 2013).

No Brasil, a renda é o critério de definição de pobreza e de extrema pobreza adotado, sendo classificadas como pobres as famílias que têm renda per capita de até 140,00 reais e como extremamente pobres aquelas que têm uma renda per capita mensal de até 70,00 reais (Ávila, 2013:110). Esses valores tiveram o reajuste de 10\% no ano de 2014. O PBF como uma política «popular», amplamente conhecida no país, é destinado às pessoas consideradas pobres, ou extremamente pobres (Ávila, 2013: 120 e Campello e Neri, 2013).

Ao completar dez anos de existência, pode ser observada no PBF a instabilidade inerente à arquitetura desta política social, que se expressa desde o cadastramento, com a não garantia do benefício mesmo para aqueles que atendem todos os critérios, até o bloqueio inesperado e não justificado do recurso, o que faria do BF um programa social e não um direito adquirido (Morton, 2013b). O benefício, que é variável, constitui-se no repasse de quantias de dinheiro mensais às pessoas cadastradas que preencham os requisitos exigidos para tal, e no caso de contempladas, que cumpram contrapartidas, chamadas de condicionalidades.

Apesar de ser concebida e financiada pelo governo federal, sua execução e fiscalização é de competência dos governos municipais. Desta forma, em cada cidade, a implementação do Programa ocorre de uma forma específica, de acordo com a estrutura da assistência social existente. Para isto um gestor municipal tem poder de decisão sobre onde e como será o cadastramento; poder de inclusão e exclusão no Sistema de Gestão de Condicionalidades do Programa Bolsa Família (Sicon); poder de interrupção temporária ou permanente do benefício, além de ter acesso às informações do Cadastro Único das famílias beneficiadas. A alteração cadastral é uma das principais ações do município no processo de gestão dos benefícios, que consiste em bloqueio, desbloqueio, cancelamento, reversão do cancelamento e suspensão dos benefícios (Ávila, 2013: 109).

Dentre as condicionalidades previstas destacam-se aquelas a serem cumpridas em equipamentos de Atenção Básica a Saúde, em especial no que se refere a atenção à saúde da família e à Segurança Alimentar e Nutricional Os compromissos previstos para os pais ou responsáveis são manter atualizado o calendário de vacinação das crianças menores de sete anos e leva-las para aferição de peso e estatura/comprimento e para serem examinadas, conforme o calendário do Ministério da Saúde. As gestantes e mães que amamentam devem participar do pré-natal e ir às consultas na unidade de saúde, após o parto devem continuar o acompanhamento da própria saúde e do bebê, além de participar das atividades educativas promovidas pelas equipes de saúde sobre aleitamento 
e alimentação saudável. Estas ações constituem práticas cotidianas que se desenvolvem em espaços mediadores significativos para a produção de conhecimento empírico sobre programas governamentais como o Bolsa Família. Assim, o objetivo deste trabalho é descrever e analisar a experiência de observação e acompanhamento do atendimento a mulheres beneficiárias em um equipamento público de saúde situado em um bairro da zona oeste do Rio de Janeiro.

\section{METODOLOGIA}

\section{Desenho da pesquisa, metodologia e narrativa textual}

A metodologia qualitativa foi baseada na perspectiva antropológica de cunho etnográfico e tem como base o material proveniente da experiência de observação e participação nos atendimentos ao longo de dois meses. As descrições etnográficas que estruturam o texto foram realizadas sem seguir uma ordem cronológica, podendo trazer eventos e relatos de dias distintos, condensados em uma mesma descrição. Estes relatos, expressos a partir da perspectiva de um sujeito coletivo que é a equipe de pesquisadoras, são situados a partir da primeira pessoa do plural, através do pronome “nós", e aparecem marcados com grafia distinta, em itálico, seguidos de reflexões que trazem uma análise pontual sobre pontos e questões específicos, de tal forma que possam ajudar a iluminar esse universo e sua compreensão.

O uso do tempo verbal no passado se mostra uma estratégia de não reificar o universo de pesquisa no tempo em que a investigação se deu, apontando para a especificidade do contexto histórico no qual conhecemos o lócus da pesquisa. Como exemplo desta especificidade, observamos uma situação de mudança dos profissionais no atendimento às beneficiárias do programa. A profissional nutricionista que acompanhamos foi substituída por uma profissional assistente social, alterando a configuração dos atendimentos. Ao final das incursões no contexto do trabalho de campo, obtivemos o contato de cinquenta e oito mulheres interessadas em participar da pesquisa, que foi aprovada pelo Comitê de Ética em Pesquisa sob o Número 449.654, de 07/11/2013 e 509.458, de $12 / 01 / 2014$. Neste artigo optamos por não revelar o nome da localidade para preservar a integridade dos agentes de saúde e das pacientes. Todos os nomes referidos no texto são fictícios.

\section{Os atendimentos}

A escolha do centro de saúde para a inserção no universo de pesquisa se apresentou como uma estratégia de acesso às beneficiárias do PBF, em função deste local ser um dos espaços de cumprimento das condicionalidades exigidas pelo Programa, em especial no que se refere a atenção à saúde da família e à segurança alimentar e nutricional. A porta de entrada no centro de saúde foi a consulta das beneficiárias com a nutricionista.

Estas consultas eram realizadas de forma coletiva, em uma sala no interior do centro de saúde. Aqueles que receberiam atendimento se acomodavam entre os assentos disponíveis dispostos em círculo, ao redor da mesa onde a nutricionista se posicionava com os documentos necessários, 
dentre eles as fichas de cadastramento e atendimento no posto, cartilhas relacionadas à nutrição e vacinação, dentre outros. Nem sempre havia espaço para todos ficarem sentados, algumas mães com seus filhos, público com maior presença nas consultas, frequentemente ficavam em pé ou encostados em alguma mesa, nas paredes ou mesmo na porta de acesso à sala.

Antes de dar início ao atendimento, Solange explicava o funcionamento do mesmo. Em nosso primeiro dia, foram passadas ao grupo informações sobre como se daria a consulta, em particular, sobre o atendimento da assistência social que deveria ser marcado separadamente ao da nutrição, sobre a pesagem que aconteceria em outra sala e ainda sobre a consulta coletiva e individual. Ela explicou que atenderia na frente de todos pois as dúvidas de pessoas diferentes poderiam ser as mesmas e assim ela poderia informar o grupo como um todo de uma só vez. Ela ressaltou, no entanto, que não teria problemas caso alguém quisesse conversar em particular/individualmente, bastando avisá-la da preferência, que eles se encaminhariam a uma sala reservada. Ao longo de nossa permanência frequentando os atendimentos, o pedido para uma conversa reservada com a nutricionista se mostrou algo raro de ocorrer.

A nutricionista durante as sessões dava informes relacionados ao acompanhamento nutricional ou orientações aos pacientes sobre procedimentos necessários para a participação nas consultas. Presenciamos com os acompanhamentos orientações sobre hipercolesterolemia e hipertensão, como a diminuição do consumo de gordura e sal. Orientações sobre diabetes e constipação intestinal, e alertas sobre os malefícios de alguns alimentos como sucos de caixinha, chamando atenção para a quantidade de açúcar e corantes, macarrão instantâneo, alertando sobre a quantidade de sal e gordura. Ela insistia sobre a praticidade e o preço não serem justificativas: "um macarrão comum também seria rápido de fazer". Ensinava receitas caseiras, desestimulando o consumo de alimentos industrializados, como uma receita de requeijão feito com iogurte desnatado, atentando para o curto prazo de validade por não haver conservantes.

Solange também dava instruções sobre o manejo da caderneta da criança, como o pedido para que a caderneta sempre fosse entregue já aberta na página em que se anota o peso e altura. Dessa forma, a pessoa responsável pela pesagem anotaria a informação direto na caderneta e não em pedaços de papel, que a sua experiência clínica demonstrava que se perdiam e atrapalhavam o acompanhamento da criança. Apesar das boas intenções com as orientações, algumas tensões não deixavam de aparecer, o que aponta para determinados elementos que não são apenas pontuais, mas se relacionam com entraves e dificuldades decorridos da prática e da vivência como usuário e profissional dos equipamentos de saúde. E em escala mais ampla, constituem problemas que afetam a própria gestão não apenas dos serviços públicos de saúde, mas das próprias políticas sociais de transferência condicionada de renda do país como um todo.

\section{A "palestra": rompendo a assimetria das posições profissional de saúde/usuário}

Naquele primeiro dia no centro de saúde, após as informações iniciais passadas 
a todos, a nutricionista fez uma breve apresentação da equipe às pessoas presentes. Disse que éramos pesquisadoras e iríamos conversar com o grupo sobre uma pesquisa a ser realizada na localidade, nos deixando em seguida à vontade para falar, enquanto ela atendia. Fomos até a frente do círculo formado pelos assentos que as pessoas ocupavam e iniciamos uma breve apresentação, explicando o contexto da pesquisa, o tema e seus objetivos, ressaltando a importância da participação delas, que fazem parte do Programa Bolsa Família, sendo, portanto, as pessoas mais indicadas a falarem sobre o que é esta política social na prática.

Enquanto falávamos, começamos a reparar nas expressões daquelas mulheres. Embora todas olhassem para nós, algumas viravam a cabeça para os lados, outras balançavam as pernas demonstrando alguma inquietude. Aquela situação em que ficávamos em pé na frente do círculo e elas sentadas nos olhando pareceu desconfortável. Depois de passarmos as explicações sobre a pesquisa e o motivo de estarmos ali, perguntamos se alguém tinha alguma dúvida e se gostariam de participar. Um silêncio ensurdecedor se fez, cortado pela fala de uma das mulheres, que perguntou o porquê da diminuição do benefício. E logo outra, aparentemente incomodada com a nossa presença, disse que aquela "palestra" que fazíamos deveria ter sido avisada com antecedência, porque daquele jeito atrapalhava o andamento do atendimento, ressaltando que ela estava ali esperando desde às $9 \mathrm{~h}$ da manhã.

Perguntamos seu nome, explicando que não se tratava de uma "palestra" e sim da apresentação de uma pesquisa, que não atrasamos o atendimento, pois a nutricionista, que naquele momento havia saído da sala para pesar uma criança, chegara há pouquíssimo tempo, e estávamos aproveitando o momento de espera para falar com o grupo. Se não estivéssemos ali, ela continuaria esperando a sua vez, ao que ela balançou a cabeça positivamente, sem mais se pronunciar sobre o assunto. A partir disso, começamos a circular pela sala para pegar os nomes e telefones das interessadas, conversando com cada uma individualmente. Ao sentarmos ao lado delas ou nos agacharmos para ficarmos na mesma altura de onde estavam sentadas, a situação mudou, conseguimos uma receptividade mais aberta e interessada. Tivemos que repetir algumas vezes a explicação sobre do que se tratava a pesquisa, conseguindo ao todo 13 contatos de mulheres que aceitaram participar. A nutricionista durante todo o tempo nos deixou bem livres no processo, e não parou os atendimentos.

O trecho etnográfico relata a nossa inserção no campo e coloca em evidência o primeiro problema que se apresentou para o desenvolvimento da pesquisa no centro de saúde, revelado pela categoria "palestra". A nossa presença no atendimento foi interpretada através desta categoria, o que apontava a existência de uma posição hierárquica que atravessava a relação entre profissionais de saúde e usuários. 
Presenciamos nos atendimentos outras situações em que as instruções dadas pela profissional também foram compreendidas como "palestra" e vistas com maus olhos pelas pacientes, evidenciado pelas falas:

Ela tinha que chegar cedo para fazer esta palestra"; "todo mundo já sabe disso, que chato, tenho hora para sair daqui"; "chega atrasada e ainda fica com essa chatice ao invés de atender logo, tenho que buscar meus filhos na escola.

O fato de termos sido introduzidas pela nutricionista influiu decisivamente para reproduzir tal relação assimétrica entre nós e o grupo, em função da própria posição hierárquica ocupada pela nutricionista ao exercer sua função naquele espaço e que foi projetada igualmente em nós quando ela nos apresentou aos presentes. Reforçando a distinção entre os papéis sociais de profissionais de saúde e usuários e a relação desigual entre eles, a própria disposição espacial, nós em pé ao centro enquanto os outros sentados ao redor, assim como a formalidade com que a apresentação se revestiu, contribuiu para reforçar essa distância inicial, realçando a percepção de que estávamos em uma posição diferente da que ocupavam ali. Sem deixar de considerar o atraso da nutricionista e sua contribuição para a impaciência da parte de alguns, soma-se ainda certo ceticismo e mesmo desconfiança comuns em momentos de encontro e interação com desconhecidos como este.

À luz da teoria do interacionismo simbólico inspirados especialmente a obra de Erving Goffman (1996) é possível extrair do episódio da nossa apresentação no atendimento no centro médico algumas questões que merecem reflexão. As categorias quando proferidas, produzem efeitos, conformam situações, demarcam posições, definem papéis, sendo elementos importantes para os enquadramentos através dos quais, como pesquisadores, somos rotulados e temos nossa presença interpretada em determinado contexto social. Ao ler a situação como uma «palestra» fica claro como em um primeiro momento, nossa definição pelo grupo se construiu de uma maneira que acentuava a distância, apontando para uma relação hierárquica entre nossas posições. A partir do momento em que começamos a atuar de maneira diferente, a relação inicial distante e assimétrica, onde nós falávamos e eles ouviam se desfez. A situação havia então mudado, tendo sido criada outra configuração, que pôde ser revertida a partir do momento em que mudamos a estratégia e passamos a conversar de igual para igual com as pessoas na sala.

Nossa interação face a face, dando margem para as pessoas falarem livremente e dando atenção ao que elas diziam, assim como nossa abordagem, pautadas pela proximidade física quando ficávamos agachadas ou sentadas ao lado das mulheres para ouvi-las e não mais em pé no centro da sala, estabeleceu uma relação em outras bases. Nas nossas representações cotidianas estamos sempre projetando uma imagem sobre nós, assim como as pessoas que conhecemos estão também fazendo uma imagem sobre quem somos. No entanto, essa imagem não é fixa e, vai mudando de acordo com o desenvolvimento da relação que construímos. A partir desse contato inicial, entendemos que a estratégia de abordagem individual era mais eficaz e, após uma breve explicação coletiva passávamos logo para as interações diretas em que podíamos explicar, mas principalmente, ouvir 
cada uma das pessoas presentes nos atendimentos.

Ao longo das nossas visitas, as pessoas que encontrávamos nunca eram as mesmas, já que o período regular para o agendamento dos atendimentos era semestral, de acordo com o prazo recomendado pelo programa. Por se tratarem de encontros semestrais, a temporalidade dos atendimentos estipulada pela política tende a contribuir para o distanciamento dos profissionais de saúde. Tal distanciamento muitas vezes se evidencia pela ausência de perspectiva, por partes dos profissionais que cumprem suas funções, de criação de vínculos com os usuários, uma vez que devem atender um grande contingente de pessoas que precisam de aconselhamento nutricional nesse sistema.

\section{O caso de Lidiane}

Lidiane parecia impaciente quando nos aproximamos para abordá-la durante a consulta no posto de saúde. Ela recebia o BF desde o início, provavelmente há 10 anos, e era mãe de oito filhos, sendo que os mais velhos tinham dezessete e dezoito anos. Contou que, quando começou a receber o dinheiro, "ajudou muito" pois ela passava por uma situação dificil, estava desempregada. O beneficio também sofreu alterações ao longo do tempo, começando com $R \$ 35,00$, passou para $R \$ 42,00$, depois $R \$ 95,00$. Ela não ia ao centro de saúde apenas para as consultas exigidas pelas condicionalidades do BF, também era usuária regular, onde ia para ter outros atendimentos médicos como dermatologista, psicólogo, ginecologista e clínico. Seus filhos pequenos também eram atendidos pelo pediatra de lá. Quando começamos a nos inteirar mais do caso dela, pudemos descobrir as razões de sua impaciência. Nossa conversa deixava flagrante algumas adversidades para a obtenção do rendimento do $B F$, relacionadas com o cumprimento das condicionalidades exigidas pelo programa.

O motivo de sua aflição durante a consulta com a nutricionista era o seu emprego. Ela havia deixado o trabalho no meio do expediente para ir ao centro de saúde, pensando que a consulta não demoraria. Trabalhando em uma creche na localidade, ela havia conseguido a autorização da diretora para ir ao centro, deixando sua colega de trabalho sozinha. Diante da situação, dizia que nossa conversa era até positiva ao seu ver porque ela conseguia se entreter, ao invés de ficar pensando no tempo de trabalho perdido com aquela espera. Ao longo de toda a reunião para consulta, ela tentava obter informações da nutricionista responsável até que, em um momento posterior ao fim da nossa conversa, a nutricionista a proibiu de interrompê-la novamente enquanto não fosse a sua vez de ser atendida, sem dar a informação que ela havia solicitado. A nutricionista se justificou dizendo que a cada vez que ela interrompia o atendimento para fazer alguma pergunta trazia como consequência o atraso no horário de todos os atendimentos e que ela deveria esperar. 
Lidiane entrou e saiu da sala ainda algumas vezes enquanto estávamos lá e em meio a essas idas e vindas, a ouvi reclamar da demora e de não poder nem dirigir a palavra à nutricionista. Ela estava preocupada com sua situação no ambiente de trabalho. Apreensiva, pensava no que a diretoria iria falar e já fazia projeções sobre como essas situações iriam favorecer uma possivel proibição ou não liberação futura por parte da creche. Ela ainda calculava o tempo que teria que ficar a mais trabalhando por conta da consulta no posto, mencionando que teria que dobrar o trabalho naquele dia.

Diversos estudos sobre o PBF em várias regiões do país indicaram uma evidente e significativa transformação das condições e dos modos de vida da população mais pobre, passando pelo empoderamento das mulheres e das crianças, pelas transformações dos padrões tradicionais de gênero e das relações familiares (Pires, 2009, 2013; Morton, 2013a; Rego, 2011). Diversas pesquisas ainda apontaram o aumento do consumo familiar, especialmente de alimentos, como um dos efeitos mais patentes da implementação do Programa (Soares e col., 2007; Correa, 2008; Pires, 2013), transformações estas que não podem ser negligenciadas.

Estes trabalhos têm revelado a heterogeneidade que atravessa o conjunto de pessoas atendidas pelo programa do governo federal, o que leva ao imperativo de analisar a implementação desta política, assim como os sentidos da renda recebida pelos seus beneficiados, levando em consideração o contexto sociocultural mais amplo no qual estes estão inseridos. É nesse sentido que gostaríamos de situar a discussão sobre as condicionalidades de saúde do programa em um contexto específico, o centro de saúde investigado, de modo a conseguir tecer algumas considerações que, no entanto, podem ocorrer em outros universos relacionados a gestão e implementação desta política.

Como foi apontado por outros estudos, as condicionalidades do PBF são um ponto chave do desenho desta política, que, no entanto, tem sido alvo de intensa polêmica relativa ao seu objetivo de inclusão social (Monnerate col., 2007). As polêmicas giram em torno de possíveis inconstitucionalidades que iriam ao sentido contrário ao direito universal à cidadania e ao acesso à saúde, assumindo um caráter coercitivo alheio às perspectivas afins à inserção social cidadã. Por outro lado, argumenta-se que estes mecanismos são fundamentais para o estímulo ao acesso aos serviços públicos de educação e saúde, vistos como medidas capazes de romperem o histórico ciclo de pobreza entre gerações. Uma questão que se coloca é da capacidade de absorção da demanda do público-alvo do PBF pelos serviços públicos de educação e saúde, e a dúvida sobre se os equipamentos públicos dos municípios teriam condições de oferecer a esta população os direitos que seriam previstos como mais básicos.

Segundo Paiva(2007), que estudou famílias beneficiárias do PBF em uma cidade satélite do Distrito Federal, as condicionalidades de saúde funcionam como "efeito placebo" à medida que os beneficiários não alteram a frequência das consultas individuais ou coletivas nos centros de saúde estudados. Segunda a autora, as ações previstas para serem cumpridas pelas famílias já são incorporadas no imaginário e nas práticas de saúde da população principalmente de crianças e 
gestantes. Por exemplo, a vacinação de crianças menores de 05 anos no Brasil apresenta-se com percentual de cumprimento em torno de $90 \%$. Esta característica revela que esta condicionalidade imposta aos beneficiários do PBF apenas ratifica uma prática de saúde consolidada no país. É importante frisar que as outras ações previstas, entre outras, o acompanhamento do crescimento, não tem percentuais tão altos como a vacinação, mas todas estão no repertório de ações dos serviços de saúde. Paiva(2007) ainda observou que o conflito em relação ao cumprimento das condicionalidades de saúde pelos beneficiários do PBFé relacionado ao Sistema Único de Saúde(SUS) que não oferece condições de acesso e acolhimento adequado aos beneficiários e refere que os problemas relacionados a restrição de consultas, longas esperas de agendamento e a descriminação dos beneficiários fazem parte das tensões enfrentadas por profissionais de saúde e beneficiários no cumprimento das condicionalidades de saúde em serviços de Atenção Básica a Saúde.

As condicionalidades de saúde do PBF ainda enfrentam desafios inerentes as características do SUS no Brasil. Infelizmente, observa-se problemas de acesso e oferta (Fonseca e Viana, 2007). Neste sentido, as ações de cuidado e assistência prestada pelos profissionais de saúde da Atenção Básica aos beneficiários do PBF devem estar consubstanciadas no ideário da humanização e do Direito Humano à Alimentação Adequada e Saudável (Ramos e Cuervo, 2012).

Nesse sentido, «a perspectiva de punir as famílias que não cumprirem as condicionalidades parece incompatível com os objetivos de promoção social do Programa”(Monnerate col., 2007: 1461). Do mesmo modo, é preciso considerar em cada localidade a oferta dos serviços de saúde, a qualidade em sua prestação e o custo pago pelas famílias para acessá-los, como custos monetários, transporte, desgaste físico consequente à locomoção e tempo de espera. Fatores estes que "refletem questões estruturais que limitam a oferta e a utilização destes serviços e comprometem sua qualidade" (Burlandy, 2007: 1448).

Vimos no caso de Lidiane que ela classifica o rendimento do PBF como uma "grande ajuda", o que entra em consonância com outras pesquisas (Ávila, 2013), nas quais o benefício é definido pelas mulheres através da categoria «ajuda» de modo bastante recorrente. Nas nossas interações com as pacientes nos atendimentos, essa era a descrição mais ouvida pelas beneficiárias, «ajuda muito», «já é uma ajuda», «apesar de pouco, ajuda bastante, alivia né?”. No entanto, ao considerarmos outros elementos do universo em que as mulheres estão inseridas, percebemos que esta ajuda acarreta ou implica determinadas dificuldades, como a necessidade de se ausentar ou faltar ao trabalho para comparecer às consultas, com o risco de serem prejudicadas ou mesmo perderem o emprego para conseguirem cumprir as condicionalidades exigidas. Como se mostrou frequente em outros casos de mulheres com quem conversamos, um ponto crítico, que atinge grande parte delas, é a dificuldade/impossibilidade de ter com quem deixar as crianças para que possam trabalhar e/ ou estudar.

A ausência ou extrema insuficiência de creches públicas nas áreas carentes das grandes 


\section{$81 / /$}

cidades é um fator incontornável para a melhoria das condições ocupacionais destas mulheres, que muitas vezes, têm que agregar o trabalho na rua ao trabalho doméstico e ao cuidado com os filhos. Outro fator ligado ao impedimento do trabalho se relaciona à existência de problemas de saúde, como uma senhora de cinquenta anos, que afirmava sofrer de problemas cardíacos, o que a debilitava e a impossibilitava de trabalhar e aumentar seus rendimentos. Nesses casos em que em função dos filhos ou de doenças as mulheres não conseguiam obter uma renda alternativa ao BF, o benefício continuava sendo considerado uma ajuda, porém insuficiente.

Como discutiremos a seguir, situações como a vivida por Lidiane ocorrem com frequência e não podem ser compreendidas sem considerarmos os desafios do Sistema Único de Saúde para atender milhares de pessoas diariamente. As demoras e atrasos nos atendimentos foram alvo de críticas por parte das beneficiárias que ouvimos. Estas, muitas vezes, têm que inserir esta obrigação no meio de outras atividades de suas rotinas, fazendo com que os atrasos atrapalhem a busca dos filhos na escola, o intervalo de trabalho, ou mesmo outros atendimentos de saúde. Por outro lado, a experiência no centro de saúde nos permitiu adentrar outros espaços, que proporcionaram a compreensão de outros fatores envolvidos no seu funcionamento e as dificuldades encontradas pelos profissionais e gestores de saúde.

\section{"O coração e a mente do centro": a vida social dos papéis}

Certo dia, após termos terminado o contato com as beneficiárias na consulta nutricional, fomos procurar a Solange para nos despedirmos. Conseguimos avistá-la dentro de uma sala onde com frequência encontrávamos uma fila de pessoas na porta. Adentramos o espaço e ficamos vendo os funcionários trabalharem. Normalmente seriam quatro funcionários trabalhando ali, mas naquele dia um deles estava de férias e outro havia faltado. Um homem, uma senhora, chamada Judith, e uma terceira mulher, que ali estava "quebrando um galho" em função das duas ausências, ficavam em uma movimentação intensa na sala que continha três mesas, uma mais perto da porta para atendimento, um pouco mais atrás outra com um computador, e uma terceira posicionada lateralmente, onde eram organizadas as fichas dos pacientes que deveriam ser atendidos no dia.

Atrás das mesas, três corredores-arquivos móveis, repletos de fichas de atendimento dos dois lados, cobriam quase toda a extensão da sala lateralmente. No outro canto, mais no fundo, ficavam caixas onde eram depositadas as fichas ao final do dia, para posteriormente serem reorganizadas nos arquivos. Judith reclamava dos «bolos» de fichas indomáveis, que estavam em permanente movimento entrando e saindo dos arquivos, dizendo que ainda havia fichas do dia anterior na caixa, que não tivera tempo para organizar. Carlos, o funcionário que lidava com as pessoas que chegavam, assistente administrativo falante e bem-humorado, após nossa apresentação pela nutricionista, se dispôs a falar sobre o que quiséssemos saber, dizendo logo que a 
quinta feira era o dia mais complicado, «no dia do Bolsa Família, isso aqui lota».

Ele nos mostrou as fichas, arquivadas do número 001 ao 87.399. Cada ficha correspondia a um usuário e essa identificação também existia no sistema digital, o GIL (Gerenciamento Interno Local), sistema que integrava toda a rede do SUS, e todos os centros médicos públicos. No entanto, cada centro só teria acesso aos pacientes de sua própria área, identificados por um número de prontuário. Carlos seguia trabalhando, o que fazia a nossa conversa ser interrompida com recorrência, porém demonstrava boa vontade em nos ajudar com informações enquanto atendia. Falava das dificuldades e da sobrecarga de trabalho nos dias de atendimento do Bolsa Família, mas na hora de definir o seu local de trabalho acabou recorrendo a uma metáfora, dizendo ser aquela sala «o coração e a mente do centro».

Quando pensamos nos profissionais que trabalham em hospitais, é comum imaginarmos pessoas vestindo jalecos brancos lidando com pacientes que os procuram em busca de solução ou alívio para seus males. No entanto, o que poderíamos chamar de "mundo da saúde", seguindo definição de mundo de Becker (1977:10), que "se constitui do conjunto de pessoas cuja ação é essencial à produção do que elas produzem, seja qual for o objeto dessa produção" envolve uma ampla gama de atores e profissões relacionados a áreas diversas. Para compreender um "mundo" específico, "todos os envolvidos são importantes" (Becker, 2008: 13) podendo ser convertidos em objetos de estudo. Cada um deles nos oferece a possibilidade de adentrar determinado mundo por um caminho e através de um ponto de vista específico, que tem a capacidade potencial de trazer à tona aspectos relativos ao tipo de pertencimento e à posição particular ocupada no universo em questão.

Da perspectiva antropológica, as descrições das práticas e das dinâmicas que constituem o trabalho desses profissionais são um material fundamental, não apenas por "contextualizar" os dados da pesquisa, mas porque esta contextualização é parte dos dados, na medida em que conferem sentido a eles. Estas informações permitem mesmo para quem jamais entrou em uma unidade básica de saúde na Zona Oeste do Rio de Janeiro, compreender ou se aproximar do que é ser usuário atendido ou um funcionário que trabalha em um centro de saúde.

Nesse sentido, é preciso considerar as palavras de Carlos quando descreve a sala da documentação como "o coração e a mente" do centro. Ele chama a atenção para o papel "vital" que a organização dos dados e a administração dos usuários ocupam no centro de saúde, sendo mesmo imprescindível para o seu funcionamento. Mesmo com a existência de uma base de dados digital, na qual os prontuários eram identificados no sistema de registro da unidade ligado ao sistema de saúde, esta tecnologia não substituía a dimensão material dos registros, já que todos os dados existentes no sistema constavam igualmente em fichas de papel, tampouco prescindia do trabalho manual necessário para lidar com esse aparato.

Antes que se criem juízos de valor sobre a ineficiência do sistema digital ou o caráter obsoleto 
ou atrasado do centro de saúde por fazer uso dessa estrutura material e manual para a administração da instituição, é preciso compreender o papel desempenhado por este arquivo dentro da prática cotidiana do centro. Inscritas em uma estrutura burocrática, através da qual o trabalho dos profissionais e o serviço de milhares de usuários eram operacionalizados, as fichas se apresentavam como mediadores centrais, na medida em que eram instrumentos técnicos que operavam o acesso aos serviços de saúde e a circulação dos usuários nestes espaços.

A antropologia, desde os trabalhos clássicos do início da disciplina, colocou os objetos no centro de suas reflexões e nas últimas décadas, os estudos com foco nos objetos e materialidades vêm se multiplicando e ampliando suas temáticas e universos de reflexão. Atentar para a vida social destas fichas, significa levar a sério o papel da materialidade na construção dos contextos sociais. Tal postura, que Appadurai (2008:16) define como "fetichismo metodológico", implica o esforço de seguir as coisas em si mesmas, de modo a ter acesso aos significados inscritos em suas formas, seus usos, suas trajetórias.

A seguir, selecionamos alguns episódios em que a mediação das fichas e as condutas a elas relacionadas, desempenhavam um papel que influía diretamente no andamento das atividades do centro médico, permitindo enxergar as dinâmicas que se inscreviam naquele espaço e as formas que adquiriam, assim como algumas das suas consequências. Neles, ganhavam destaque as questões relativas ao tempo, em especial, a relação problemática que se estabelecia entre as fichas em sua função de ordenação dos atendimentos, e a adequação ao tempo, cujo cálculo não repousava em critérios precisos.

\section{As fichas e o tempo: desafios em torno da ordenação}

Como costumava acontecer, Solange chegava aquele dia para iniciar o atendimento com pilhas de fichas. Após avisar sobre a ausência da assistente social e dar orientações quanto a importância de levar o cartão de vacina, não só o da criança como o do adulto, e de que eles estivessem em dia, Solange informou ao grupo sobre a ordem de atendimento. Assinalou que não era ela quem decidia, pois apenas seguia a ordem de chegada, correspondente à posição em que as fichas se encontravam quando the entregavam. Ao longo das consultas, outra funcionária, vestida com um jaleco branco, entrava na sala trazendo mais pilhas de fichas, que eram depositadas em cima da mesa onde a nutricionista atendia aqueles chamados pelo nome.

Com o tempo, fomos percebendo alguma recorrência com os problemas relacionados à ordem do atendimento. Esta era determinada pela posição na qual a ficha era colocada na mesa, quando separada no momento em que o usuário se apresentava na sala de documentação. As fichas continham, afixados por um clips, um pedaço de papel com a categoria de atendimento, "Nutrição" e ainda o horário de chegada da paciente, como 9:20h. Porém, como observamos no dia em que acompanhamos o trabalho do 
pessoal do setor administrativo, algumas pessoas reclamavam de que suas fichas não se encontravam na sala de atendimento, mesmo diante do fato de terem chegado cedo.

Enquanto permanecíamos na sala, ao menos duas mulheres apareceram sinalizando este problema, na esperança de conseguirem uma solução. Nesse momento, Solange que se encaminhava para sair da sala de documentação, ao pegar uma pilha de fichas da nutrição, se aproximou de nós comentando "ele me dá a ficha de quem chegou agora [era por volta de 11:40h] e não entrega de quem chegou às sete". Ao deixar a sala,um grupo de pacientesse aproximou para lhe perguntar informações. Solange, que mal havia escutado,falou logo, ao mesmo tempo em que se desvencilhava para seguir seu caminho: "a senhora vai ter que entrar na fila, e perguntar, não posso fazer nada".

Enquanto observávamos a sala e o serviço, a todo instante chegavam pessoas para pegar o número para o atendimento, marcar consultas ou fazer eventuais reclamações ou pedir informações. A fila em frente à sala crescia, à revelia dos esforços e da intensa movimentação dos funcionários para lidar com todas as demandas e procedimentos.

Certa ocasião, ao abordarmos uma mulher que esperava na fila sobre o motivo de estar ali, ela confirmou ser a fila para marcar as consultas elou pegar o número de atendimento. Também à espera para o atendimento da nutricionista, outra mulher explicou que a marcação era para todas as especialidades, e no dia marcado, era preciso ir até a unidade para pegar o número do atendimento. Segundo seu relato, naquele dia ela havia chegado às 5:30h da manhã para conseguir ser uma das primeiras, porém já eram quase 10 h e ela ainda aguardava.

$\mathrm{Na}$ medida em que fazem a mediação entre os pacientes e os profissionais e constituem os mecanismos de acesso das pessoas ao serviço de saúde, estas fichas ganham centralidade, sendo os elementos procurados pelos pacientes e em torno dos quais conflitos e tentativas de negociações são feitas. Não sabemos explicar o que aconteceu com o destino das fichas daquelas pessoas de quem presenciamos a reclamação, mas não seria difícil imaginar que em meio a quase noventa mil fichas, acessadas em grande volume diariamente, algumas acabassem por se desviar de seu devido curso em meio aos muitos deslocamentos e procedimentos necessários ao funcionamento daquela estrutura burocrática.

Em se tratando de um programa de transferência condicionada de renda que exige contrapartidas relacionadas à educação e à saúde das crianças, dados de pesquisa que apontem para as dificuldades e barreiras envolvidas no cumprimento ou não dessas condições são bem-vindos, especialmente porque uma série de juízos de valor acaba recaindo sobre muitas mulheres por não conseguirem cumprir tais condicionalidades. Podemos tomar como exemplo a própria conversa em que o funcionário administrativo Carlos, exprime sua percepção sobre as beneficiárias do Bolsa Família, 
de acordo com a qual

“elas só vem porque vão perder, quando vão à loteria, aparece a mensagem dizendo 'voltar ao posto para pesar'. Elas vêm obrigadas, senão não vinham não... Elas perdem o cartão do Bolsa Família, aquele verdinho... nem todo mundo do bolsa família é humilde".

Por outro lado, ouvimos relatos de beneficiárias cujas percepções identificavam um tratamento diferenciado, oscilando entre falta de simpatia e preconceito, para os pacientes que integravam o PBF, identificados por alguns funcionários como «o pessoal do bolsa». Trevisani (2012) apontou como possíveis causas desse fato o «desenho intersetorial» do $\mathrm{BF}$, cuja consequência seria a ausência de um entendimento claro sobre as responsabilidades do serviço de saúde, fazendo «com que o PBF acabe sendo visto como um programa da assistência social, desenvolvido na unidade de saúde, o que traz resistências para o envolvimento da equipe. Os titulares, por vezes, não são vistos e tratados como usuários do SUS, por direito" (Trevisani, 2012: 190).

Aqui não almejamos atribuir alguma culpa ou mesmo transferir responsabilidades, mas fornecer subsídios empíricos para uma compreensão mais próxima dos contextos sociais em que a política abstrata é operacionalizada na prática, com o intuito de mostrar as relações e complexidades envolvidas, de modo a problematizar concepções e perspectivas que qualificam o programa e seu público-alvo sem levar em consideração a realidade cotidiana em que políticas como essa se efetivam. A vida social se constitui a partir de eventos, causalidades e relações múltiplas e o descumprimento das condicionalidades não parece tratar-se simplesmente de uma questão de escolha racional, de falta de informação ou mesmo de negligência. Esperamos fornecer uma contribuição ao debate mostrando os elementos em jogo que afetam na prática o cumprimento destas condições e, consequentemente, a permanência no programa, que, em nosso caso, estão relacionados à gestão dos equipamentos públicos de saúde e a tudo que a envolve.

Nesse sentido, após mostrar as formas nas quais a organização e movimentação das fichas se relacionam à questão do tempo, especialmente quando ocorrem falhas em seu ordenamento que afetam a posição dos usuários na fila de atendimento, podemos desdobrar esta problemática do tempo, apontando outras situações em que ela apareceu, como por exemplo, a dificuldade mencionada por muitas mulheres para comparecerem ao posto de saúde, relacionadas às limitações já mencionadas como o horário do trabalho, do colégio das crianças. Estes fatores se aliam ao conjunto da imprevisibilidade e da impossibilidade de um cálculo preciso em relação ao tempo que podem perder no atendimento por causa dos atrasos.

Dessa forma, muitas vezes a situação encontrada se aproxima da descrita por Trevisani (2012:190): “As condicionalidades são consideradas por alguns profissionais e diretores como assistencialistas e burocráticas e pelos titulares como obrigações para que mereçam o benefício. Não existe compreensão do motivo e do objetivo das condicionalidades pelos titulares, e para os 
profissionais e gestores de unidade, não existe consenso nenhum sobre isso."

“É paciente, mas é amigo»: contornos da burocracia na comunidade_

Observando Carlos desempenhando suas funções de atendimento aos usuários que chegavam ao centro, pudemos também ouvir suas histórias sobre o trabalho ali, ao mesmo tempo em que acompanhávamos a execução de suas tarefas em vista dos problemas e imprevistos que surgiam no momento. Ele comentou o exemplo da documentação, dizendo que, antes mesmo de conseguir chegar a constar em uma das fichas, adquirindo um número de prontuário, os usuários deviam possuir documentos válidos, o que se apresentava como um obstáculo para muitos. Vimos Carlos orientando pessoas com informações sobre os documentos necessários ou mesmo sobre os próprios procedimentos burocráticos para acesso àqueles registros.

Ele reclamava conosco sobre as beneficiárias do Bolsa Familia que muitas vezes chegavam ao posto com os filhos sem possuir qualquer registro. Afirmando com uma pergunta que "a criança não pode ficar sem atendimento, né?", descrevia o procedimento que adotava nesses casos. Se a criança não tivesse registro, ele tinha que abrir uma fich a provisória e pedir para a mãe providenciar a certidão para que então a criança pudesse pertencer ao sistema, tendo um número de prontuário definitivo.

Em seguida, chegava à sala uma adolescente com uma criança reclamando da ficha que não estava no consultório do médico e que era atendimento de emergência. Diante do nosso estranhamento por se tratar de uma unidade de atenção básica onde não havia emergência, Carlos disse que costumava deixar alguns números "extras" para estes casos, já que sempre chegava uma criança com febre, com dor, e como nunca tinha pediatra na UPA do bairro, era corriqueiro as mães recorrerem ao centro nestes casos. Dessa forma, ele conseguia "encaixa-las" no atendimento.

Em determinado momento, ainda conversando conosco, Carlos apontou para uma pessoa na fila e disse, "a paciente na fila, a gente se encontra aqui, mas se encontra na quadra da escola de samba, no mercado...», e frisava, "aqui é comunidade», "é tudo amigo, é paciente, mas é amigo». Nesse momento, quando ele deixava a sala para ir almoçar, chegou um senhor conhecido para lhe perguntar algo. Ele nos olhou como se confirmasse o que havia falado há pouco sobre os «pacientes amigos». Aparentemente o senhor precisava de um laudo médico para o INPS e Carlos pediu para que voltasse mais tarde que ele veria o que poderia fazer.

Após a descrição dos espaços, dos objetos e da atividade dos funcionários administrativos, não há dúvidas de que estamos lidando com uma estrutura burocrática, da qual o Estado moderno é inteiramente dependente, tal como salientam as teorias sociológicas sobre o assunto. No centro de saúde estudado, encontramos uma administração baseada em documentos escritos e um saber 


\section{$87 / /$}

técnico, no entanto, a observação e a narrativa de Carlos fornecem uma imagem distinta daquela consagrada por tais teorias. Sobretudo, porque há nestas teorias uma ênfase no caráter "impessoal" do trabalho burocrático, como uma das condições necessárias ao bom funcionamento de todo o sistema. De acordo com Weber (1971:251), além de segregar a atividade oficial como algo distinto da esfera da vida privada, e da posição do cargo ocupado (integrado nas condições funcionais objetivas dadas pelo mecanismo baseado na disciplina) não estabelecer relações pessoais, a burocracia assumiria um caráter "desumanizado", "na medida em que consegue eliminar dos negócios oficiais o amor, o ódio, e todos os elementos pessoais, irracionais e emocionais que fogem ao cálculo".

Assistente social de formação, Carlos, ao definir o centro de saúde como «comunidade», qualifica as relações sociais que ali se estabelecem, onde as pessoas «se conhecem», se encontram em outros contextos da localidade como a «quadra da escola de samba» e «são amigas», apesar de serem «pacientes» quando estão na fila do posto. Isso aponta para sentidos distintos daqueles assumidos pela definição abstrata e teórica da burocracia como pautadas pela lógica racional-legal, pelo conhecimento técnico e seus códigos normativos e, marcadamente, pela impessoalidade. Através da percepção de Carlos sobre a prática cotidiana em seu universo de trabalho, a burocracia assume contornos locais que servem como pistas de análise a serem consideradas e investigadas. Sua narrativa remete a um contexto em que os usuários dos serviços públicos de saúde estabelecem relações pessoais e compartilham, para além dos minutos da consulta ou da fila, uma experiência de vivência em comum em um território.

O uso do termo «comunidade», hoje amplamente difundido como substituto do termo pejorativo favela, teve sua emergência na década de 1950, com a atuação do Bispo Dom Helder Câmara, principal responsável por uma grande campanha em defesa dos favelados do Rio de Janeiro e, sua iniciativa de criação da cruzada de São Sebastião. Tais ações constituíram uma virada na representação política da favela, com o reconhecimento e a promoção dos seus moradores ao estatuto de comunidade, e consequentemente, a sujeito político potencialmente autônomo, rompendo assim com a imagem puramente negativa e com o estigma abatido e reproduzido na imprensa sobre a favela e seus habitantes (Valladares, 2005: 77,78). No entanto, é preciso estar atento para não incorrermos em algumas armadilhas que podem acompanhar a noção de «comunidade», especialmente, o cuidado para não reificar uma ideia de união e de solidariedade, quando muitas vezes estes territórios também são marcados pelo conflito, além do mascaramento da diversidade interna, da multiplicidade de interesses ali presentes (Valladares, 2005:159), ou ainda das amplas relações existentes da favela com o seu exterior em vários níveis, que perpassam interesses políticos, econômicos e outros (Machado da Silva, 2011).

A partir do material etnográfico obtido com as incursões ao centro de saúde e do acompanhamento dos atendimentos nutricionais com as mulheres que integram o PBF, temos elementos que ajudam a problematizar as perspectivas que se orientam a partir de definições normativas da pobreza, como uma condição, associada à falta de perspectivas e à estrita carência. Neste enquadramento, marcado 
pela visão negativa da falta, as ações dos sujeitos são justificadas pela necessidade e seus meios de vida caracterizados pela ótica da «precariedade». As descrições e dados que apresentamos estabelecem contrapontos a esta visão, que não favorece a percepção da dimensão que poderíamos chamar de "cooperação», conceito bastante discutido nos estudos relacionados às economias informais (Millar, 2010), mas também reconhecível nas práticas observadas no funcionamento do serviço público no centro médico.

Portanto, mesmo em contextos considerados carentes ou com infraestrutura material ou pessoal insuficientes, devemos atentar para a sociabilidade e as formas como os sujeitos se relacionam entre si e com o ambiente no qual estão inseridos. O olhar etnográfico, voltado para os diversos tipos, níveis e formas de relações estabelecidas, pôde evidenciar dimensões produtivas presentes nesses universos. No contexto do centro de saúde na «comunidade» estudada, empecilhos ou dificuldades burocráticas conseguiam ser contornados através do recurso às relações, seja com os colegas de trabalho substituindo ou cobrindo aqueles ausentes por motivos diversos ou com funcionários tentando resolver, dentro das margens permitidas pelos procedimentos técnicos adequados, os problemas diversos que as pessoas apresentavam ao buscarem atendimento.

Mesmo diante do contexto cotidiano no centro de saúde nos quais problemas e tensões não estavam ausentes e da tendência ao distanciamento e certa desumanização inerente à lógica burocrática, Carlos mostrava que os usuários do centro em uma «comunidade» não eram apenas fichas, números e horários em uma lista. Eles eram conhecidos, «pessoas» e não «indivíduos», como na distinção atribuída por DaMatta (1997), mas que assume aqui outros contornos sociológicos, distintos daqueles ideológicos que circunscrevem tais práticas a dois sistemas ou códigos de conduta complementares, como o «sabe com quem está falando» ou o «jeitinho», que seriam característicos da sociedade brasileira, fazendo «o brasil, Brasil» (DaMatta, 1986).

O que buscamos ressaltar é o papel produtivo e o fato significativo de como as populações de baixa renda mobilizam relações sociais e suas redes locais, como recursos e estratégias que conformam um campo de possibilidades de ação e modos de vida. Estas são características que não se restringem ou se explicam através de uma «cultura brasileira» herdada ou reproduzida, pelo contrário, são práticas muito mais abrangentes, que ocorrem em diversos contextos envolvendo escassez de recursos monetários e populações diversas pelo mundo - das ilhas do pacífico (Sahlins, 1997:108) ao Haiti (Neiburg eNicaise2010) e à África (Hart, 1973) - e as formas que assumem, assim como as motivações dos indivíduos que as empreendem não seguem um padrão ou lógica homogênea, devendo ser investigadas empiricamente.

Perguntas sobre «por que indivíduos ou grupos recorrem a laços familiares, organizações formais, redes de troca e outras estratégias - ainda precisam ser respondidas» (Small e col., 2011:94) e o melhor, talvez único, caminho para alcançar estas respostas é o campo. É preciso não apenas "ouvir a voz dos pobres" (Rego, 2011), mas observar e investigar na prática como estes sujeitos, se é que se definem como "pobres", conferem sentido às suas situações, opções e decisões atuais, 
como as explicam e como efetivam tais ações no mundo social no qual estão inseridos. A atenção a essa perspectiva pode ser um caminho para evitar rotulações e estigmatizações que possam recair moralmente sobre esta população.

\section{CONCLUSÃO}

O desenho institucional do Programa Bolsa Família impõe uma série de atribuições e obrigatoriedades que recaem sobre os serviços públicos de saúde, tanto em relação aos seus usuários como aos seus gestores e profissionais, criando uma tensão entre as partes que precisam se adequar a essas demandas. Os fatores relacionados ao cuidado e assistência às beneficiárias do PBF na Atenção Básica, baseados nas questões discutidas neste artigo, revelaram alguns destes aspectos limitantes e tensões que profissionais de saúde enfrentam cotidianamente e as formas como os compreendem e tentam contorná-los. A análise demonstra a complexidade de fatores que incidem sobre o cumprimento das condicionalidades do PBF nas unidades de saúde, problematizando perspectivas que tendem a responsabilizar moralmente as mães, apontando a sua conduta como os fatores exclusivos dos quais as contrapartidas dependem para serem realizadas.

Neste sentido, a compreensão da condicionalidade como Direito Humano a Alimentação Saudável e Adequada deve ser refletida à luz da realidade do Sistema Único de Saúde, sobretudo na Atenção Básica de Saúde, com profissionais de saúde capacitados e em condições de lidar e respeitar a realidade social das beneficiárias. O país investiu numa política de combate à pobreza $\mathrm{e}$ à fome e seu caráter estruturante deve contemplar também o reflexo desta política na melhoria do Sistema Único de Saúde de forma não coercitiva e provisória mas, como meio de inserção social. Se a temporalidade se mostrou um desafio e fator problemático diante da capacidade de ordenação da dinâmica de serviços de atenção básica à saúde, a humanização apareceu como estratégia capaz de contornar as adversidades para contribuir, por meio da compreensão intrínseca e extrínseca do Programa Bolsa Família, na melhoria e fortalecimento do Sistema Único de Saúde.

\section{REFERÊNCIAS BIBLIOGRÁFICAS}

APPADURAI, A. Introdução: Mercadorias e a política de valor. In: A vida social das coisas, as mercadorias sob uma perspectiva cultural. Niterói: EDUFF, 2008, p16.

ÁVILA, M. Que pensam as beneficiárias do Bolsa Família? Política \& Trabalho, UFPB, João Pessoa n. 38, Abril de 2013, pp. 105-122.

BECKER, H. "Mundos artísticos e tipos sociais", In: Gilberto Velho (org.), Arte e sociedade. Rio de Janeiro, Zahar, 1977, p10.

BECKER, H. Outsiders: Estudos de sociologia do desvio. Rio de Janeiro, Jorge Zahar, 2008, $\mathrm{p} 13$. 
BURLANDY, L. Transferência condicionada de renda e segurança alimentar e nutricional. Ciência \& Saúde Coletiva, vol. 12, núm. 6, dezembro, 2007, pp. 1441-1451.

CAMPELLO, T.; NERI, M. (orgs.) Programa Bolsa Família: uma década de inclusão e cidadania. Brasília: IPEA, 2013. 494p.

CORREA, C. Participação do Programa Bolsa Família nas modificações do consumo alimentar de famílias beneficiadas pelo programa. 2008. Disponível em: $<$ http://www.ipc-undp. org/publications/mds/28P.pdf>Acesso em: 18.dez. 2014

DAMATTA, R. "Sabe com quem está falando? Um ensaio sobre a distinção entre indivíduo e pessoa no Brasil". Carnavais, malandros e heróis: para uma sociologia do dilema brasileiro. Rio de Janeiro: Rocco, 1997. 6.ed.

DAMATTA, R. O que faz o brasil, Brasil?. Rio de Janeiro: Rocco, 1986. 2. ed.

FONSECA, A.M.M; VIANA, A.L.A. Direito à saúde, atenção básica e transferências condicionadas de renda na América Latina. Ciênc. Saúde coletiva [online], vol.12 no.6 Rio de Janeiro Nov./Dec. 2007, pp. 1505-1512.

GOFFMAN, E. A representação do eu na vida cotidiana. Petrópolis, Vozes, 1996 [1959], 7.ed.

HART, Keith. "Informal Income Opportunities and Urban Employment in Gana."TheJournalof ModernAfricanStudies,v.11, n.1(mar.,1973), 1973. pp. 61-89.

MACHADO DA SILVA, L. A. [1967] 2011. “A política na favela.” DILEMAS: Revista de Estudos de Conflito e Controle Social 4( 4): 699-716.

MENEZES, F; SANTARELLI, M. Da estratégia 'Fome Zero' ao plano 'Brasil Sem Miséria': Elementos da seguridade social no Brasil. Rio de Janeiro: IBASE, 2003. Disponível em http:// www.ibase.br/pt/wp-content/uploads/2013/02/proj-fomezero.pdf. Acesso em: Out. 2014

MILLAR, K. "Cooperation in the Informal Economy: The Case of Recyclers at a Brazilian Garbage Dump”. Cooperation in social and economic life. Altamira Press. 2010.

MONNERAT, G. L. et al. Do direito incondicional à condicionalidade do direito: as contrapartidas do Programa Bolsa Família. Ciência \& Saúde Coletiva 2007; 12(6):1453-1462.

MORTON, G. Acesso à permanência: diferenças econômicas e práticas de gênero em domicílios que recebem Bolsa Família no sertão baiano. Política \& Trabalho, UFPB, João Pessoa n. 38, Abril de 2013a, pp. 43-67. 
MORTON, G. O verdadeiro culpado do boato sobre o Bolsa Família. Jornal Brasil de Fato, 11 jul. 2013. Disponível em: www.brasildefato.com.br/node/13555. Acesso em 11 jul. 2013.

NEIBURG, F; NICAISE, N. Lixo. Estigmatizações, comércios, políticas - Déchets. Estigmatisations, commerce, politiques - Garbage. Stigmatisations, comerce, politics - Fatra. Stigmatizasyon, Komès, polítik. Porto Príncipe, Haiti; Rio de Janeiro: Viva Rio; NuCEC, 2010.

PAIVA, V.F. Programa Bolsa Família: uma avaliação do perfil sócio-econômico e das condicionalidades da saúde com famílias da Ceilândia. 2007, 119p. Dissertação (Mestrado em Nutrição Humana) - Universidade de Brasília. Distrito Federal.

PIRES, F. A Casa Sertaneja e o Programa Bolsa Família. Questões para Pesquisa. Política \& Trabalho, UFPB, João Pessoa, v.27, 2009, p. 1 -15.

PIRES, F. Comida de criança e o Programa Bolsa Família: moralidade materna e consumo alimentar no semiárido. Política \& Trabalho, UFPB, João Pessoa n. 38, Abril de 2013, pp. 123 135.

RAMOS, C.I;CUERVO, M.R.M. Programa Bolsa Família: a interface a atuação profissional e o direito humana a alimentação adequada. Ciência \& Saúde Coletiva, v.17(8), 2012, pp. 21592168

REGO, W. L.; PINZANI, A. Vozes do Bolsa Família: autonomia, dinheiro e cidadania. São Paulo: Editora UNESP, 2011.

SAHLINS, M. 'O 'pessimismo sentimental' e a experiência etnográfica: por que a cultura não é um ‘objeto' em vias de extinção (Parte II)” Mana, vol. 3, 1997, p108.

SMALL, M S.; HARDING, D ; LAMONT, M. Reavaliando cultura e pobreza. Sociologia\& Antropologia | v.01.02: 91-118, 2011.

SOARES, F. RIBAS, R. OSÓRIO, R. Avaliando o Impacto do Programa Bolsa Família: uma Comparação com Programas de Transferência Condicionada de Renda de Outros Países. Centro Internacional de Pobreza (IPEA/PNUD). 2007. Disponível em:http://www.undp-povertycentre. org/pub/port/IPCEvaluationNote1.pdf. Acesso em: Nov. 2014

TREVISANI, J. de J. D. Avaliação da implementação das condicionalidades de saúde do Programa Bolsa Família e seu papel no cuidado à saúde - estudo de caso do município do Rio de Janeiro. 2012, p190. Tese (Doutorado em Saúde Pública) - Universidade de São Paulo, 2012.

VALLADARES, L. A invenção da favela: do mito de origem à favela. Rio de Janeiro, Editora FGV, 2005, pp. 77-78, 159. 
$92 / /$

WEBER, M. "Burocracia” Ensaios de Sociologia. Zahar, 1971, 2a ed, p 251.

Artigo apresentado em 21-01-15

Artigo aprovado em 12-09-15

Artigo publicado no sistema em 22-12-15 